\title{
Prevalence of coronary artery disease and nation's responsibility towards patients
}

\author{
Prof. D. B. Karki \\ MBBS, MRCP (UK), FRCP(Edin), FNAMS, FACC, \\ Professor \& Head, Department of Medicine, Kathmandu Medical College Teaching Hospital
}

$\mathrm{T}$ The burden of coronary artery disease worldwide is alarming ${ }^{1}$. The burden of coronary artery disease and its risk factors are going to be national health problems even for Nepal as the number of patients with this disease is expected to increase rapidly.

Ischaemic heart disease (IHD) is the number one cause of death in adults from both low and middle income countries as well as from high income countries ${ }^{1}$. On the basis of 2007 mortality data, more than 2200 Americans die of cardiovascular diseases each day, an average of one death every 33 seconds ${ }^{2}$. The incidence of Coronary artery disease is expected to increase by approximately $29 \%$ in women and $48 \%$ in men in the developed countries between 1990 and 2020. The corresponding estimated increase in developing countries was $120 \%$ in women and $137 \%$ in men $^{3}$.

According to World Health Organization estimates, 16.6 million people died of cardiovascular diseases (CVD) in 2001 and developing countries contributed to 78\%. It also estimates, nearly 25 million people will die of CVD by $2020^{4}$. The incidence of coronary artery disease is declining in the developed countries; on the other hand it is increasing in the developing countries. In the Atherosclerotic Risk in Community (ARIC) Study, in participants aged 45-64 years, Coronary artery disease incidence rates per 1000 person-years were 12.5 in white men and 10.6 in black men ${ }^{5}$. About 3.8 million men and 3.4 million women worldwide die each year from coronary artery disease ${ }^{6}$.

The incidence of coronary artery disease goes on increasing as one gets older and is more prevalent in male. The life time risk of developing coronary heart disease in persons aged 40 years is $49 \%$ in men and 32 $\%$ in women. At the age of 70 years, the life time risk is 35 $\%$ in men and $24 \%$ in women ${ }^{7}$.

There are very few studies about the prevalence of coronary artery disease in Nepal. Studies of prevalence of coronary artery disease in a population Study at Dharan Municipality performed by Vaidya $A$ et al have revealed the prevalence of coronary artery disease to be $5.7^{8}$.

The diagnostic work-up for patients showing signs and symptoms of Ischemic heart disease is expensive and not easily affordable and accessible to the patients in Nepal. A few private hospitals and nursing homes provide these services but at costs not many Nepalese people can afford. In addition to this, even after diagnosis of IHD, the treatment is expensive, thus leaving many patients stranded without treatment. Invasive procedures including Coronary angioplasty with stenting or bypass, indicated in many patients with coronary artery disease, are available only in selected centres in Nepal at costs not affordable to the average Nepalese population.

Every nation has responsibility towards the health of its citizen. People do not die of treatable diseases due to lack of financial aids in most of the developed countries of the world. Patients who do not have health insurance are looked after by the nation. Even in our country, government should have a policy of providing free medical service to non-affording patients. Special procedures like Coronary angioplasty and coronary bypass surgery should be provided to non-affording patients by the nation.

The government has an important role in the prevention and treatment of Coronary artery disease in Nepal. In a country like ours which is already burdened by numerous communicable diseases, prevention of non-communicable diseases like IHD should be the major goal rather than struggling for cure later on. The government should thus, start awareness programmes on prevention of Coronary artery disease as part of primary prevention. Secondary prevention may be done even at primary health centres by keeping patients with risk of coronary artery disease on routine follow up and referring high-risk cases to higher centres. The ministry of health should establish a fully equipped national 
centre for cardiac diseases along with regional cardiac centres that provide affordable services to the general population along with a well-defined referral system. Promoting research in this field is another important step the government should take in order to plan further developments and decide what needs to be done. With combined efforts by the medical society and the government, the predicted epidemic of coronary artery disease and its consequences could be avoided.

\section{References}

1. Lopez AD, Mathers CD, Ezzati M, Jamison DT, Murray CJ. Global and regional burden of disease and risk factors, 2001. Systematic analysis of population health data. Lancet. 2006;367(9524):1747.

2. American Heart Association. Heart Disease and Stroke Statistics-2003 Update.

3. Yusuf S, Reddy S, Qunpuu S, Ananda S. Global burden of cardiovascular diseases: Part 1 :General considerations, the epidemiologic transition, risk factors, and impact of urbanization. Circulation. 2001;104(22):2746.

4. Murray CJ, Lopez AD. The Global burden of cardiovascular Diseases : A comprehensive Assessment of mortality and Disability from Disease, Injuries and Risk factors in 1990 and projected to 2020. Cambridge Mass: Harvard school of public health, 1996.

5. JONES DW, Chambless LE, Folsom AR, Heiss G, Hutchinson RG, Sharrett AR, Szklo M,Taylor

Jr. Risk factors for coronary heart disease in African Americans : The Atherosclerotic Risk in Communities Study, 1987 - 1997. Arch Intern Med. 2002;162:2565-2571.

6. WHO. The Global burden of disease 2004 Update [Internet]. Geneva: World Health Organization. 2008. Available from: http://www.searo.who.int/ LinkFiles/Reports_GBD_report_2004update_full. pdf.

7. Lloyd Jones DM, Larson MG, Beiser A, Levy D.Life time risk of developing coronary heart disease. Lancet. 1999;353(9147):89-92.

8. Vaidya A, Pokharel PK, Nagesh S, Karki P, Kumar S, Majhi S. Prevalence of Coronary Heart Disease in the Urban Adult Males of Eastern Nepal: A populationbased cross-sectional study. Indian Heart J. 2009;61(4):341-7. 